\title{
Diaphragmatic Hernia after Adult Orthotopic Liver Transplantation: A Rare Surgical Complication Associated to Immunosuppression?
}

\author{
Klaus Steinbrück ${ }^{1 *}$, Reinaldo Fernandes ${ }^{1}$ and Marcelo Enne ${ }^{2}$ \\ ${ }^{1}$ Hepatobiliary Surgery Unit, Bonsucesso Federal Hospital - Health Ministry, Rio de Janeiro, Brazil \\ ${ }^{2}$ General Surgery Department, Ipanema Federal Hospital - Health Ministry, Rio de Janeiro, Brazil
}

\begin{abstract}
Diaphragmatic Hernia (DH) after adult Orthotopic Liver Transplantation (OLT) is a rare event with only two cases reported in English literature. It is not clear if this complication is related to surgery or to immunosuppression therapy or both. We describe a well-resolved case of left-sided DH in a 43-year-old man taking Tacrolimus and mycophenolate mofetil (MMF) as immunosuppressants, 27 months after OLT. Authors from previously reported cases considered that ascites and incisional hernia, as well as Mammalian Target Of Rapamycin (mTOR) inhibitors therapy, as predisposing factors for $\mathrm{DH}$ development. In the case presented here, none of the possible surgical triggering factors described before were present. MMF is associated to impaired wound healing and incisional hernias, like mTOR inhibitors. Maybe minor and not evident diaphragmatic injury during hepatectomy associated to immunosuppression with mTOR inhibitors and/or MMF have an important role in DH occurrence after OLT in adults.
\end{abstract}

Keywords: Diaphragmatic hernia; Orthotopic liver transplantation; Immunosuppression

\section{Introduction}

Diaphragmatic hernia (DH) after adult Orthotopic Liver Transplantation (OLT) is a rare event. To the best of our knowledge, there are only two cases reported in English literature [1,2]. It is not clear if this complication is related to surgery or to immunosuppression therapy or both. Herein, we report a case of left-sided DH after OLT in adult and discuss this theme.

\section{Case Report}

A 43-year-old man was admitted with epigastric pain, vomiting and bowel obstruction for 48 hours. He denied fever or gastrointestinal bleeding. Leukocytosis $\left(18,000 / \mathrm{mm}^{3}\right)$ and elevated CRP $(35.2 \mathrm{mg} /$ dL) were present. Liver enzymes and bilirubin were normal. Physical examination revealed dehydration, tachycardia and painful epigastrium palpation. Twenty seven months before he had been submitted to OLT for cirrhosis due to primary sclerosing cholangitis associated to Crohn's Disease. Transplantation and post-operative period occurred uneventful. No injury to the diaphragm or preexisting Bochdalek hernias were observed during surgery. At the time of OLT, patient status was: Child-Pugh score B8, MELD score 28 and absence of ascites. Immunosuppression has been done with Tacrolimus (through level 8 $\mathrm{ng} / \mathrm{ml}$ ) and Mycophenolate Mofetil (MMF) $720 \mathrm{mg}$ twice daily.

Chest $\mathrm{x}$-ray showed elevated left hemidiaphragm and hydroaerial level in left hemithorax (Figure 1). CT scan confirmed leftsided diaphragmatic hernia with pleural effusion, lung parenchymal compression on the same side and heart deviation to contralateral side (Figure 2). Patient was submitted to left thoracotomy and an eight $\mathrm{cm}$ sized defect was detected in left hemidiaphragm. The gastric fundus, epiploon and a segment of transverse colon were found to be herniated into the thorax, but no signs of necrosis were observed. After decompressing the stomach with a nasogastric tube, herniated organs could be delivered into the abdomen and the diaphragmatic defect was repaired by simple sutures with polypropylene. Oral feeding and immunosuppressive drugs were resumed on the third post-operative day. Patient received empiric antibiotic therapy (ciprofloxacin and metronidazole) for seven days and CRP levels return back to normal $(1.2 \mathrm{mg} / \mathrm{dL})$. He was discharged 8 days after surgery and is doing well 31 months after diaphragmatic hernia repair.

\section{Discussion}

Diaphragmatic herniation after adult OLT is an exceptional event. We found only two cases reported in English literature [1,2]. Wagner et al. [1] reported a case of right-sided DH four years after OLT, in a 58-year-old woman receiving Everolimus, MMF and corticosteroids to treat allograft rejection [1]. In this case, patient had massive ascites at the time of transplantation. Authors believe that increased intraabdominal pressure, due to ascites, caused diaphragmatic muscle weakness, predisposing herniation. Rossetto et al. reported a case of a 58-year-old man, with a large incisional hernia that developed left-sided DH 16 months after OLT [2]. He was takin Sirolimus as immunosuppressant. Before admission, he suffered from retching with alimentary vomiting. Authors suggest that incisional hernia was

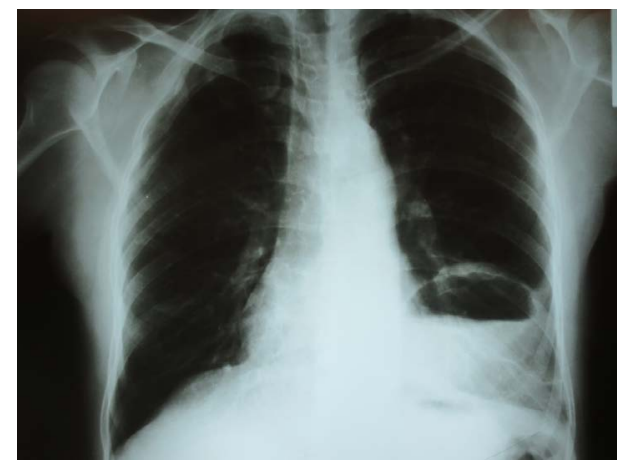

Figure 1: Chest x-ray image showing elevated left hemidiaphragm and hydroaerial level in left hemithorax.

*Corresponding author: Klaus Steinbrück, Hepatobiliary Surgery Unit, Bonsucesso Federal Hospital - Health Ministry, Rio de Janeiro, Brazil, Tel: +55-2139779811; E-mail: steinbruck@gmail.com

Received September 29, 2015; Accepted November 14, 2015; Published November 21, 2015

Citation: Steinbrück K, Fernandes R, Enne M (2015) Diaphragmatic Hernia after Adult Orthotopic Liver Transplantation: A Rare Surgical Complication Associated to Immunosuppression? J Clin Case Rep 5: 644. doi:10.4172/2165-7920.1000644

Copyright: (c) 2015 Steinbrück K, et al. This is an open-access article distributed under the terms of the Creative Commons Attribution License, which permits unrestricted use, distribution, and reproduction in any medium, provided the original author and source are credited. 


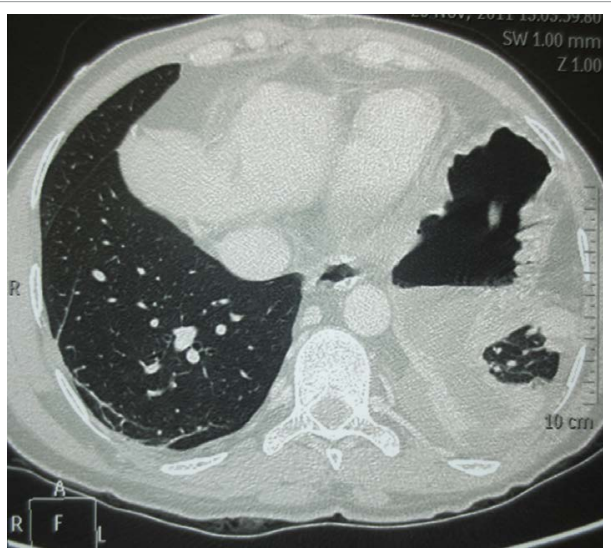

Figure 2: CT scan image showing left-sided diaphragmatic hernia with pleural effusion, lung parenchymal compression on the same side and heart deviation to contralateral side.

an accessory factor for diaphragmatic herniation since it could have induced a more vigorous contraction of the diaphragm muscle to reach an intra-abdominal pressure so effective to induce vomiting, might causing diaphragm rupture. In addition, they suggest that a probable iatrogenic vascular injury (even in the absence of visible iatrogenic damage during hepatectomy) strengthened by the anti-proliferative and antiangiogenetic effects of Sirolimus [3-5], could have contributed to the spontaneous diaphragmatic rupture.

In the case presented here, none of the possible surgical triggering factors described before were present. No evident injury to diaphragm, excessive bleeding (needing extreme use of energy device for hemostasis) or preexisting Bochdalek hernias were observed during hepatectomy. Patient had no ascites or incisional hernia that could contribute to diaphragm muscle weakness or distension. There are cases of $\mathrm{DH}$ after partial liver transplantation (living donor, split and reduced graft) [6,7], in which herniation is attributed to an unprotected area in the right diaphragm. As our patient received a full-size adult liver graft, no unsupported space was present in this case.

Regarding immunosuppression, the two cases reported before, were receiving mammalian target of rapamycin (mTOR) inhibitors (Everolimus and Sirolimus) [1,2]. This class of drugs is related to incisional hernias and impaired wound healing after transplantation [3,4,8]. Adani et al. [9] consider that the use of mTOR inhibitors in both cases had an important role in diaphragmatic herniation, as it could have weaken the previously damaged diaphragm structure, facilitating a spontaneous rupture [9]. Our patient was taking Tacrolimus and MMF. Like mTOR inhibitors, the use of MMF is a risk factor for impaired wound healing and incisional hernias [4,10,11], probably because of its antiproliferative effect, that may interfere with the healing of the muscles and fascia. We belive that the hypothesis advocated by Adani et al. for diaphragmatic herniation in the previous cases, may be considered for our patient too, with MMF playing the role of mTOR inhibitors. In this case, we suggest that development of DH after OLT in adults is related to the surgical procedure (diaphragmatic muscle injury during hepatectomy, even if not evident) and the immunosuppressant regimen (mTOR inhibitors and/or MMF).

As only three cases (including this one) of DH after OLT in adults have been reported so far, we can only speculate about the physiopathology of this complication. However, it is the first step for further discussion.

\section{References}

1. Wagner D, Iberer F, Sereinigg M, Kniepeiss D, Kornprat $P$, et al. (2010) Massive Diaphragmatic Herniation Following Orthotopic Liver Transplantation in an Adult. Liver Transplantation 16: 783-785.

2. Rossetto A, Baccarani U, Adani GL, Lorenzin D, Bresadola V, et al. (2011) Diaphragm rupture in a liver transplant patient under chronic immunosuppressive therapy with sirolimus: rare complication after liver transplantation. Updates Surg 63: 51-53.

3. Toso C, Meeberg GA, Bigam DL, Oberholzer J, Shapiro AM, et al. (2007) De novo sirolimus-based immunosuppression after liver transplantation for hepatocellular carcinoma: long-term outcomes and side effects. Transplantation 83: $1162-1168$

4. Kahn J, Müller H, lberer F, Kniepeiss D, Duller D, et al. (2007) Incisiona hernia following liver transplantation: incidence and predisposing factors. Clin Transplant 21: 423-442.

5. Guba M, von Breitenbuch P, Steinbauer M, Koehl G, Flegel S, et al. (2002) Rapamycin inhibits primary and metastatic tumor growth by antiangiogenesis: involvement of vascular endothelial growth factor. Nat Med 8: 128-135.

6. Shigeta T, Sakamoto S, Kanazawa H, Fukuda A, Kakiuchi T,et al. (2012) Diaphragmatic hernia in infants following living donor liver transplantation: Report of three cases and a review of the literature. Pediatr Transplantation 16: $496-500$

7. Perwaiz A, Mehta N, Mohanka R, Kumaran V, Nundy S, et al. (2010) Rightsided diaphragmatic hernia in an adult after living donor liver transplant: a rare cause of post-transplant recurrent abdominal pain. Hernia 14: 547-549.

8. Feldmeyer L, Hofbauer GF, Böni T, French LE, Hafner J (2012) Mammalian target of rapamycin (mTOR) inhibitors slow skin carcinogenesis, but impair wound healing. $\mathrm{Br} J$ Dermatol 166: 422-424.

9. Adani GL, Rossetto A, Bresadola V, Baccarani U (2010) Diaphragm Rupture in a Liver Transplant Patient Receiving Chronic Immunosuppressive Therapy with Sirolimus. Liver Transplantation 16: 1220.

10. Barba J, Rosell D, Rincon A, Robles JE, Zudaire J, et al. (2012) New Immunosuppressive Therapies and Surgical Complications After Renal Transplantation. Transplantat Proc 44: 1275-1280.

11. Humar A, Ramcharan T, Denny R, Gillingham KJ, Payne WD, et al. (2001) Are wound complications after a kidney transplant more common with modern immunosuppression? Transplantation 72: 1920-1923. 